\title{
A Polymer Blend Electrolyte Based on CS with Enhanced Ion Transport and Electrochemical Properties for Electrical Double Layer Capacitor Applications
}

\author{
Shujahadeen B. Aziz 1,2,*(D), Elham M. A. Dannoun ${ }^{3}$, Muhamad H. Hamsan ${ }^{4}$, Hewa O. Ghareeb ${ }^{5}$, \\ Muaffaq M. Nofal ${ }^{6}{ }^{\circ}$, Wrya O. Karim ${ }^{5}$, Ahmad S. F. M. Asnawi ${ }^{7}$, Jihad M. Hadi ${ }^{8}$ (D) and \\ Mohd Fakhrul Zamani Abdul Kadir ${ }^{4}$
}

check for updates

Citation: Aziz, S.B.; Dannoun, E.M.A.; Hamsan, M.H.; Ghareeb, H.O.; Nofal, M.M.; Karim, W.O.; Asnawi, A.S.F.M.; Hadi, J.M.; Kadir, M.F.Z.A. A Polymer Blend Electrolyte Based on CS with Enhanced Ion Transport and Electrochemical Properties for Electrical Double Layer Capacitor Applications. Polymers 2021, 13, 930. https://doi.org/ $10.3390 /$ polym 13060930

Academic Editor: Pablo A. García-Salaberri

Received: 21 February 2021

Accepted: 4 March 2021

Published: 17 March 2021

Publisher's Note: MDPI stays neutral with regard to jurisdictional claims in published maps and institutional affiliations.

Copyright: (c) 2021 by the authors. Licensee MDPI, Basel, Switzerland. This article is an open access article distributed under the terms and conditions of the Creative Commons Attribution (CC BY) license (https:/ / creativecommons.org/licenses/by/ $4.0 /)$.
1 Hameed Majid Advanced Polymeric Materials Research Lab., Department of Physics, College of Science, University of Sulaimani, Qlyasan Street, Sulaimani 46001, Iraq

2 Department of Civil Engineering, College of Engineering, Komar University of Science and Technology, Sulaimani 46001, Iraq

3 General Science Department, Woman Campus, Prince Sultan University, P.O. Box 66833, Riyadh 11586, Saudi Arabia; elhamdannoun1977@gmail.com

4 Centre for Foundation Studies in Science, University of Malaya, Kuala Lumpur 50603, Malaysia; hafizhamsan93@gmail.com (M.H.H.); mfzkadir@um.edu.my (M.F.Z.A.K.)

5 Department of Chemistry, College of Science, University of Sulaimani, Qlyasan Street, Sulaimani 46001, Iraq; hewa.ghareeb@univsul.edu.iq (H.O.G.); wrya.karim@univsul.edu.iq (W.O.K.)

6 Department of Mathematics and General Sciences, Prince Sultan University, P.O. Box 66833, Riyadh 11586, Saudi Arabia; muaffaqnofal@gmail.com

7 Chemical Engineering Section, Universiti Kuala Lumpur Malaysian Institute of Chemical \& Bioengineering Technology (UniKL MICET), Alor Gajah, Malacca 78000, Malaysia; asyafiq.asnawi@s.unikl.edu.my

8 Department of Medical Laboratory of Science, College of Health Sciences, University of Human Development, Sulaimani 46001, Iraq; jihad.chemist@gmail.com

* Correspondence: shujahadeenaziz@gmail.com

Abstract: The fabrication of energy storage EDLC in this work is achieved with the implementation of a conducting chitosan-methylcellulose- $\mathrm{NH}_{4} \mathrm{NO}_{3}$-glycerol polymer electrolyte system. The simple solution cast method has been used to prepare the electrolyte. The impedance of the samples was fitted with equivalent circuits to design the circuit diagram. The parameters associated with ion transport are well studied at various plasticizer concentrations. The FTIR investigation has been done on the films to detect the interaction that occurs among plasticizer and polymer electrolyte. To get more insights into ion transport parameters, the FTIR was deconvoluted. The transport properties achieved from both impedance and FTIR are discussed in detail. It was discovered that the transport parameter findings are in good agreement with both impedance and FTIR studies. A sample with high transport properties was characterized for ion dominancy and stability through the TNM and LSV investigations. The dominancy of ions in the electrolyte verified as the $t_{\text {ion }}$ of the electrolyte is established to be 0.933 whereas it is potentially stable up to $1.87 \mathrm{~V}$. The rechargeability of the EDLC is steady up to 500 cycles. The internal resistance, energy density, and power density of the EDLC at the 1 st cycle are $53 \mathrm{ohms}, 6.97 \mathrm{Wh} / \mathrm{kg}$, and $1941 \mathrm{~W} / \mathrm{kg}$, respectively.

Keywords: polymer blend; plasticizer; ion transport; EEC modeling; FTIR deconvolution; TNM and LSV study; EDLC device

\section{Introduction}

In the past few years, researchers have been deeply concerned about global issues regarding sustainable energy sources that are safe for the environment. The most prominent electrolyte used in batteries and supercapacitor industries is an electrolyte in the liquid form. A liquid electrolyte (LE) provides high ionic conductivity due to its low bulk resistance but has drawbacks like leakage of harmful gases or corrosive liquid [1]. Researchers are 
attracted to study solid polymer electrolytes (SPEs). They are easier to handle due to their free-standing properties compared to LEs. Rapid technology development is needed in this era due to massive commercial demands on various electrical devices with different shapes and sizes. These demands can be solved with the implementation of SPEs [2]. Several advantages of SPEs include them being lightweight, of excellent thermal stability, high flexibility, cheap, and easy handling $[3,4]$.

Plastic production worldwide has been boosted from $\sim 2$ million tons in 1950 to 8.3 billion tons in 2015. This is approximately an increase of $76 \%$ and results in increasing waste production. This plastic waste is in the environment, landfills, and oceans [5]. This is the main reason that biopolymers are studied in order to find alternatives to current non-biodegradable polymers. The most commonly studied marine biopolymer is chitosan (CS). CS can be a good ionic conductor due to its chemical structure (existence of $\mathrm{OH}$ and $\mathrm{NH} 2$ ) [6]. Methylcellulose (MC) is another biopolymer with great potential to be used in polymer electrolyte applications. MC is extracted when alkali-based cellulose is treated with methyl chloride. Its basic structural units are joined by $\beta-(1 \rightarrow 4)$ glycosidic bond $[7,8]$. Polymer blend, a method used in this work, is a straightforward process where two or more polymers form a superior material [9]. This is because the functional groups of each polymer interact with each other and provide more pathways for ions. CS and MC possess functional groups with lone pair electrons which are beneficial in ionic transportations.

A lot of ionic sources are available for SPE applications such as sodium, lithium, magnesium, potassium, silver, copper, and ammonium salts. This work is focused on the use of ammonium salts to fabricated protonic $\left(\mathrm{H}^{+}\right)$energy devices. $\mathrm{H}^{+}$can be obtained not only from ammonium salts but also from inorganic acids like sulfuric acid $\left(\mathrm{H}_{2} \mathrm{SO}_{4}\right)$ and phosphoric acid $\left(\mathrm{H}_{3} \mathrm{PO}_{4}\right)$. Reports on these acids show a chemical degradation which is not good for energy device applications [10,11]. Ammonium nitrate $\left(\mathrm{NH}_{4} \mathrm{NO}_{3}\right)$ is chosen in this work owing to its stumpy lattice energy of $648.9 \mathrm{~kJ} \mathrm{~mol}^{-1}$. This value can be considered low compared to other ammonium salts, e.g., for ammonium acetate $\left(\mathrm{NH}_{4} \mathrm{CH}_{3} \mathrm{CO}_{2}\right)$, ammonium sulfate $\left(\left(\mathrm{NH}_{4}\right)_{2} \mathrm{SO}_{4}\right.$, and ammonium phosphate $\left(\left(\mathrm{NH}_{4}\right)_{3} \mathrm{PO}_{4}\right)$, the values are 703.1, 1754.7, and $3334.0 \mathrm{~kJ} \mathrm{~mol}^{-1}$, respectively. In addition, lattice energy for ammonium bromide $\left(\mathrm{NH}_{4} \mathrm{Br}\right)$, ammonium chloride $\left(\mathrm{NH}_{4} \mathrm{Cl}\right)$ and ammonium fluoride $\left(\mathrm{NH}_{4} \mathrm{~F}\right)$ is 682.0, 708.0 and $834.0 \mathrm{~kJ} \mathrm{~mol}^{-1}$, respectively [12,13]. A low lattice energy salt provides more free ions and all of these free ions can thus contribute to the energy storage process of the energy devices.

The process of energy storage for an electrochemical double-layer capacitor (EDLC) involves a non-Faradaic reaction which means that ions build a charge double-layer on the carbon-based electrodes [14]. It has been reported that EDLC has higher power density and easier fabrication methods compared to Faradaic capacitor or pseudocapacitor [15-17]. Activated carbon is the most commonly used active material in the electrodes of an EDLC [18-20]. Various activated carbons have been synthesized from different sources such as nori-based [21], tofu-based [22], dimocarpus longan-based [23], coconut shell-based [24], and many more. Unique properties of activated carbon such as excellent electron conductivity, reasonable price, easy handling, and good chemical stability, plus high surface area mark it a choice for EDLC applications [25]. In this effort, CS is blended with $\mathrm{MC}$ to form a polymer matrix. Ions are provided by the addition of $\mathrm{NH}_{4} \mathrm{NO}_{3}$ and glycerol. The electrolyte with the best performance will be chosen to be used in the EDLC fabrication.

\section{Experimental Methods}

\subsection{Electrolyte Preparation}

The preparation of polymer electrolytes was performed from the components of MC (4000 cP), CS (MW 310,000-375,000 g/mol), and low MW glycerol plasticizer. In a separate flask, CS:MC polymer blends were prepared by dissolving $30 \mathrm{wt} \% \mathrm{MC}$ and $70 \mathrm{wt} \%$ of CS in $40 \mathrm{~mL}$ of $1 \%$ acetic acid at ambient temperature for about $3 \mathrm{~h}$. The two solutions were then combined and stirred for further $2 \mathrm{~h}$ in order to obtain a homogeneous solution. To this 
solution, $40 \mathrm{wt}$.\% of $\mathrm{NH}_{4} \mathrm{NO}_{3}$ was added. Plasticization of the resulting CS:MC polymer blend solutions was performed by adding different quantities of 14, 28, and $42 \mathrm{wt} . \%$ glycerol. The obtained samples were denoted as MCCSNH1, MCCSNH2, and MCCSNH3, correspondingly. The contents of these samples were poured into the plastic petri dishes to cast the fabricated films, which were subsequently dried at ambient temperature. Prior to characterizations, the films were further dried using silica gel desiccant.

\subsection{Characterization Techniques}

\subsubsection{FTIR and EIS Analyses}

HIOKI $3531 \mathrm{Z}$ Hi-tester was implemented to gain the impedance spectra of all samples over a frequency range $\mathrm{f}=50 \mathrm{~Hz}-1000 \mathrm{kHz}$. Small pieces of $2 \mathrm{~cm}$ in diameter were cut from the films to prepare discs, which were placed between the two stainless steel (SS) electrodes underneath a spring pressure.

Moreover, Fourier transform infrared (FTIR) spectroscopy analysis was also carried out to investigate the interaction and complexation among the polymers, salt, and plasticizer. The FTIR analysis in this work was employed using a Spotlight 400 Perkin-Elmer spectrometer with $1-\mathrm{cm}^{-1}$ resolution in the range of $500-4000 \mathrm{~cm}^{-1}$. To further support the ionic conductivity studies, the ionic transport parameters; number density $(n)$, ionic mobility $(\mu)$, and diffusion coefficient $(D)$ based on the percentage of free ions were identified. The deconvolution method via the Gaussian-Lorentzian function was used to extract overlapping peaks as well as to correct the baseline of the curves.

\subsubsection{Transference Number Analysis (TNM)}

Transference number analysis (TNM) was conducted at a working voltage of $0.20 \mathrm{~V}$ using a V\&A Instrument DP3003 digital DC power supply. The data were used to prove the involvement of ions in the entire conductivity. The electrolyte was sandwiched in between stainless steel (SS) electrodes. The summation of electronic $\left(t_{e}\right)$ and ionic $\left(t_{i}\right)$ transference number is equal to 1 , where both values can be acquired from the subsequent equation:

$$
t_{i}=\frac{I_{i}-I_{s S}}{I_{i}}
$$

where $I_{S S}$ and $I_{i}$ are the steady-state current and initial current, respectively. The circuit for TNM structure is shown in Figure 1.

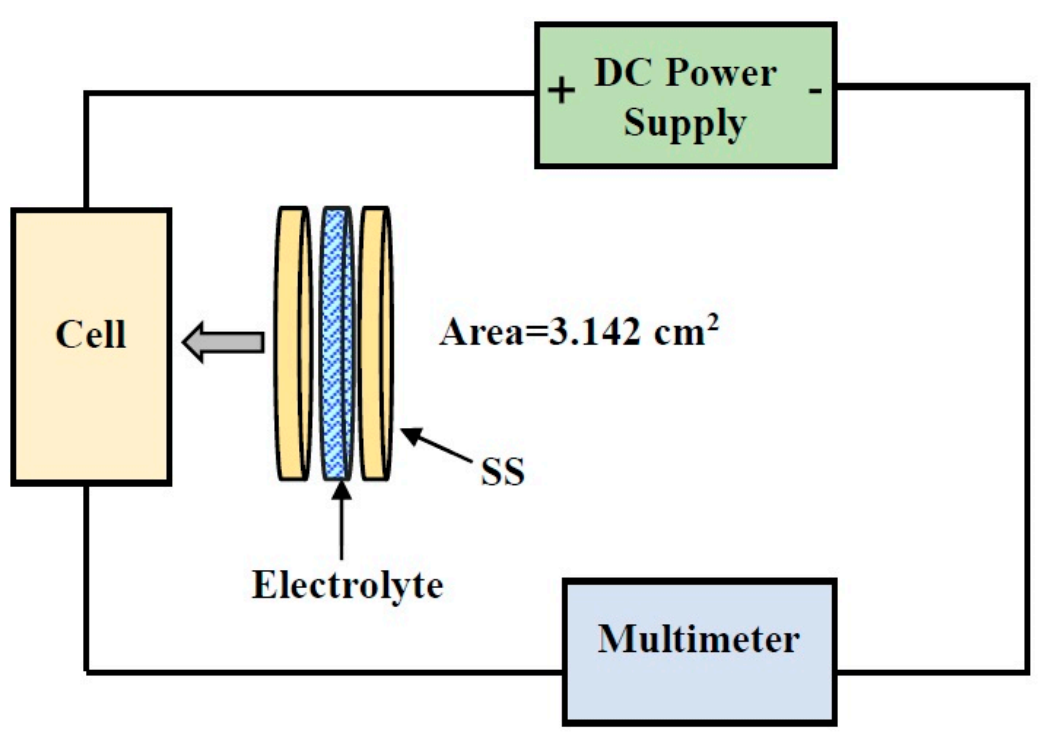

Figure 1. Circuit setup for Transference Number Analysis (TNM) measurement. 


\subsubsection{Linear Sweep Voltammetry (LSV)}

The LSV analysis was performed using a Digi-IVY DY2300 potentiostat at a $0.02 \mathrm{~V} / \mathrm{s}$ scan rate. The highest conducting sample was mounted in a Teflon holder with SS electrodes.

\subsubsection{Steps to Fabricate EDLC and Their Characterization}

Mixing and pulverization of $0.25 \mathrm{~g}$ of carbon black (CB) and $3.25 \mathrm{~g}$ of activated carbon (AC) powders were carried out using a planetary ball miller (XQM-0.4) at a rotation speed of $50 \mathrm{rpm}$ for $15 \mathrm{~min}$. Meanwhile, polyvinylidene fluoride (PVDF) as a binder was stirred in $15 \mathrm{~mL}$ of N-methyl pyrrolidone (NMP) solvent. Dissolution of the AC-CB powder mixture in the NMP-PVDF solution resulted in the formation of a thick black solution, which then varnished on an Al-foil using a doctor blade. After oven drying of the coated foil at 60 ${ }^{\circ} \mathrm{C}$, the dried electrodes were cut into circular samples with area of $2.01 \mathrm{~cm}^{2}$. The prime conducting electrolyte was situated between two carbon electrode CR2032 coin-type cells. As shown in Figure 2, these coin cells of EDLC were positioned in Teflon holders for further examination. The charge-discharge for the EDLC was measured using a Neware battery test system (current density $=0.5 \mathrm{~mA} / \mathrm{cm}^{2}$ ). The equations below are allowed calculating each specific capacitance (C), equivalent series resistance (ESR), efficiency, energy density $(\mathrm{E})$, and power density $(\mathrm{P})$ of the EDLC.

$$
\begin{gathered}
C=\frac{i}{x m} \\
E S R=\frac{V_{d}}{i} \\
\text { efficiency }=\frac{t_{d i s}}{t_{c h a}} \times 100 \% \\
E=\frac{C V}{2} \\
P=\frac{V^{2}}{4 m E S R}
\end{gathered}
$$

where $i$ is the current apply, $x$ the slope of discharge part, $V_{d}$ is the drop voltage and $m$ stands for the mass of activate material used. The times for discharge and charge parts are given as $t_{d i s}$ and $t_{c h a}$, respectively.

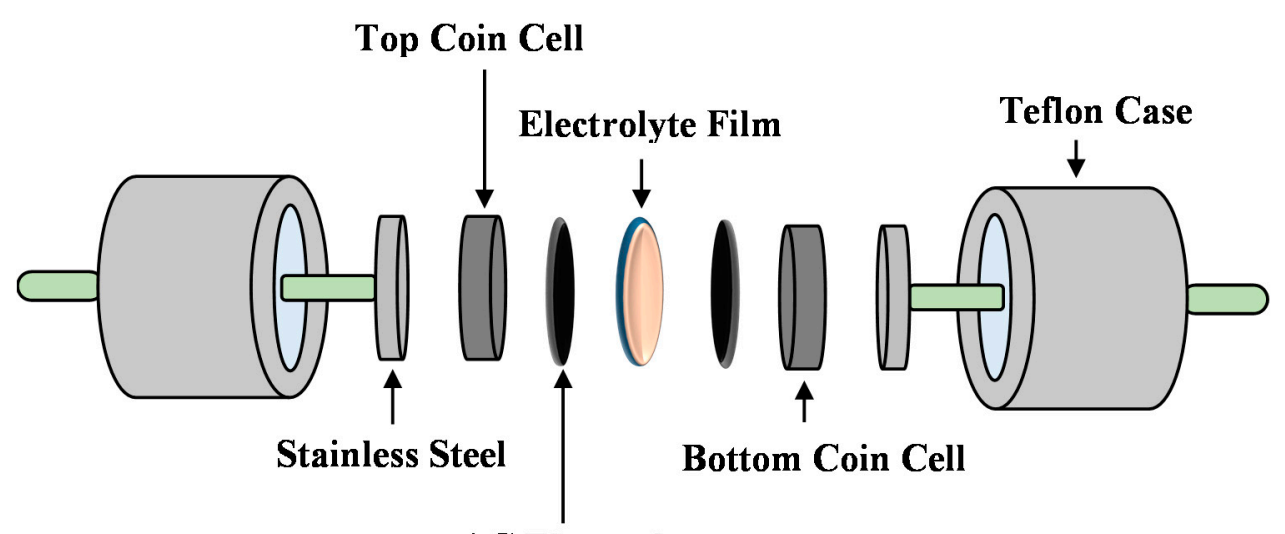

\section{AC Electrode}

Figure 2. Illustration of the fabricated electrochemical double-layer capacitor (EDLC). 


\section{Results and Discussion}

\subsection{Impedance Study}

PEs as part of an innovative class of materials are widely applied in devices [26]. Many investigational studies have confirmed the importance of adding low molecular weight plasticizers into the PEs for enhancing ion migration [27]. A significant role of impedance spectroscopy is the investigation of the electrical properties of a large variety of electrolyte materials and the electrode-electrolyte interfaces [28-30]. The impedance plots for the CS:MC: $\mathrm{NH}_{4} \mathrm{NO}_{3}$ :glycerol system are depicted in Figure 3A-C. When the circuit composed of a capacitor and a resistor in parallel, the ideal impedance spectra should be a standard semicircle having a diameter-matched with the real axis. The absence of the high-frequency semicircular region indicates that the ions are primarily responsible for the conduction [31-33]. However, the presence of the spike at the low-frequency region results from the electric double-layer capacitance at the blocking electrodes [34-37]. As obviously seen in Figure $3 \mathrm{~A}-\mathrm{C}$, the absence of the semicircles at the high-frequency region is owed to the use of the plasticizer [38]. This relation below is employed to calculate the impedance of $C P E\left(Z_{C P E}\right)[39,40]$ :

$$
Z_{C P E}=\frac{1}{C \omega^{p}}\left[\cos \left(\frac{\pi p}{2}\right)-i \sin \left(\frac{\pi p}{2}\right)\right]
$$

where $C, \omega$ and $p$ stand for the CPE capacitance, the angular frequency and the deviation measure of the plot from the axis, respectively. The CPE is connected in series with the $R_{b}$ of the electrolytes and their EIS signals only display the spike [41]. The impedance can be mathematically represented as follows [42]:

$$
\begin{gathered}
Z_{r}=\frac{\cos \left(\frac{\pi p}{2}\right)}{C \omega^{p}}+R_{b} \\
Z_{i}=\frac{\sin \left(\frac{\pi p}{2}\right)}{C \omega^{p}}
\end{gathered}
$$

These equations are also used in the fitting parameters (CPE1 and CPE2) and determined the $R_{b}$ values precisely. The resulting $R_{b}$ values and CPE values for the CMNG1, CMNG2, and CMNG3 electrolytes are listed in Table 1. The high values of CPE2 with the addition of glycerol can be explained on the basis of increasing the number of ions in the electrolytes. This results in an increase in the accelerating electrode polarization; thereby, an increase in the capacitance value at low frequency [43]. The addition of glycerol as a plasticizer enhances salt dissociation and hence increases ion mobility $[44,45]$.

From Equation (10), the ionic conductivity $(\sigma)$ can be calculated as the measure of the electrical properties of the electrolytes. The calculation also comprises $R_{b}, t$, and $A$ values as charge resistance, thickness, and surface area, respectively. From Table 1, the conductivity values for the electrolytes are expressed by:

$$
\sigma=\frac{t}{A \times R_{b}}
$$

Commonly the $\sigma_{d c}$ can be stated as follows [46]:

$$
\sigma_{d c}=\Sigma q n \mu
$$



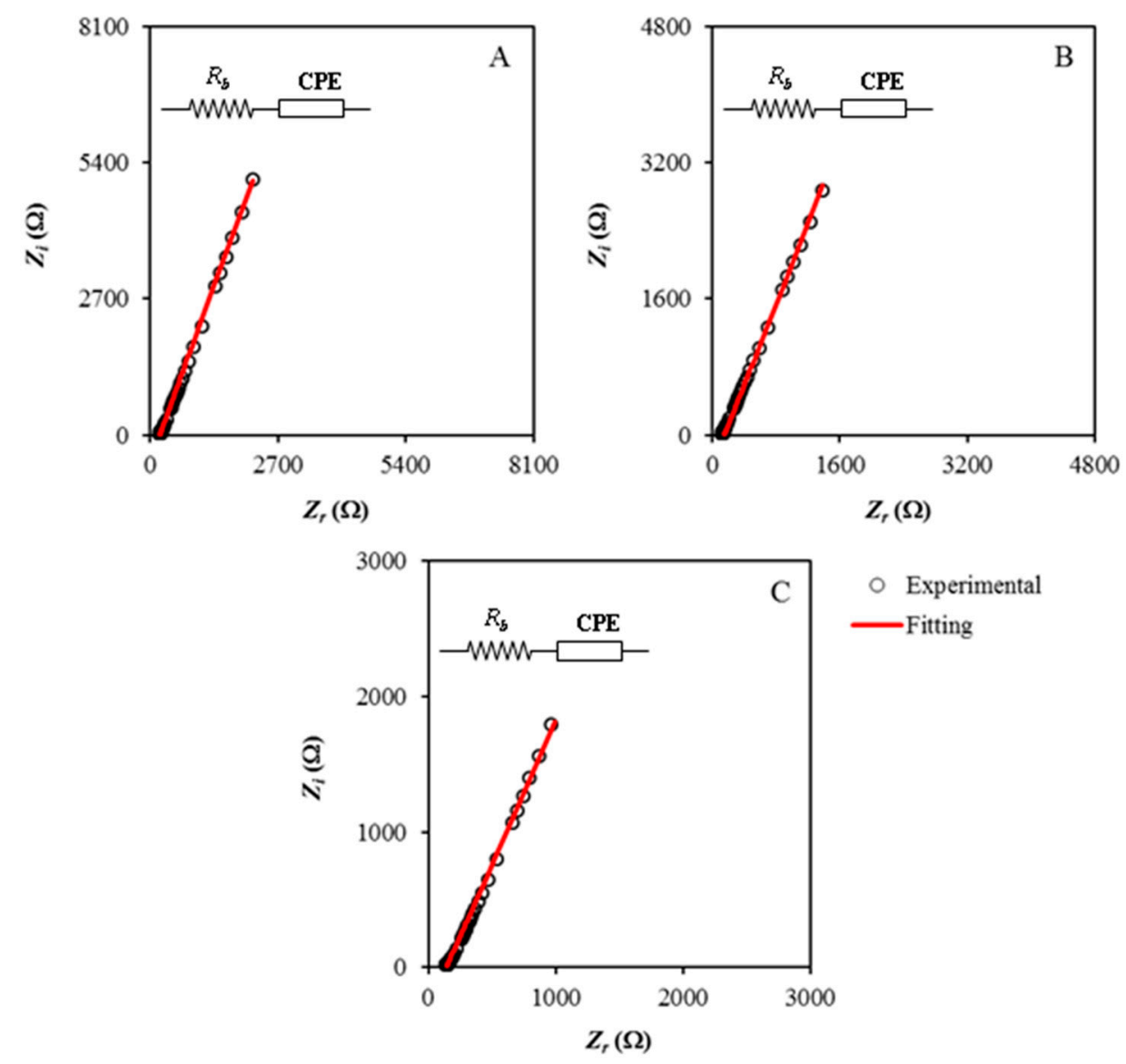

Figure 3. Nyquist plots of the electrolytes of (A) CMNG1, (B) CMNG2 and (C) CMNG3, respectively, at room temperature. The inset figure is the suitable electrical equivalent circuit.

Table 1. Room temperature ionic conductivity and circuit elements for the plasticized polymer electrolytes (PPEs).

\begin{tabular}{ccc}
\hline Electrolyte & $\boldsymbol{R}_{\boldsymbol{b}}(\mathbf{O h m})$ & Conductivity $\left(\mathbf{S ~ c m}^{\mathbf{- 1}}\right)$ \\
\hline CMNG1 & 200 & $6.97 \times 10^{-5}$ \\
CMNG2 & 150 & $1.16 \times 10^{-4}$ \\
CMNG3 & 140 & $1.31 \times 10^{-4}$ \\
\hline
\end{tabular}

Previous investigations established that the $\mathrm{H}^{+}$ion released by ammonium ion is considered as the charge carrier species in such polymer/ammonium salt systems [47]. The extra plasticizer amended the number of charge carriers $(n)$ through further salt dissociation and increase mobility $(\mu)$ by providing huge amorphous phases. Some equations can be applied to calculate the transport parameters such as diffusion coefficient $(D)$, mobility $(\mu)$, and number density $(n)$ of ions from impedance data possessing only a spike [48]. Beginning with the calculation of the D of ionic species, the following equation is employed:

$$
\begin{gathered}
D=D \circ \exp \left\{-0.0297\left[\ln D_{\circ}\right]^{2}-1.4348 \ln D \circ-14.504\right\} \\
D \circ=\left(\frac{4 k^{2} l^{2}}{R_{b}{ }^{4} \omega_{\min }{ }^{3}}\right)
\end{gathered}
$$

where $l$ is the electrolyte thickness, $\omega_{\min }$ is the angular frequency at the minimum $Z_{i}$ value. 
The mobility $(\mu)$ of the ionic species is determined from Equation (14),

$$
\mu=\left(\frac{e D}{K_{b} T}\right)
$$

where $T$ is the absolute temperature and $k_{b}$ is the Boltzmann constant.

Since DC conductivity of ions is obtainable from Equation (10), the density of ion carriers $(n)$ can be determined from Equation (11). In Table 2, the parameters associated with the ion transport for all the systems are listed. There is a clear trend of increasing both values of $D$ and $\mu$ with increasing glycerol quantity from 14 to $42 \mathrm{wt} . \%$. These correlations are related to the chain flexibility enrichment in the presence of glycerol. The same trend of increasing $n$ with increasing glycerol quantity is observed. All these, in turn, result in an increase in conductivity. A possible explanation of this is the role of glycerol molecules in enhancing the salt dissociation, thereby raising the number density of ion carriers [48]. In addition, the attractive forces between the anions and cations of the salt are greatly lowered [49]. Consequently, a higher number of $\mathrm{NH}_{4}{ }^{+}$ions $\left(n_{i}\right)$ is created by $\mathrm{NH}_{4} \mathrm{NO}_{3}$ into the polymer.

Table 2. The values of $D, \mu$, and $n$ at room temperature.

\begin{tabular}{cccccc}
\hline Electrolyte & $\boldsymbol{n}\left(\mathbf{c m}^{-3}\right)$ & $\boldsymbol{\mu}\left(\mathbf{c m}^{\mathbf{2}} \mathbf{V}^{-\mathbf{1}} \mathbf{s}^{-\mathbf{1}}\right)$ & $\boldsymbol{D}\left(\mathbf{c m}^{\mathbf{2}} \mathbf{s}^{-\mathbf{1}}\right)$ & $\boldsymbol{p} \mathbf{( r a d})$ & $\left.\mathbf{C P E}{ }^{*} \mathbf{F}\right)$ \\
\hline CMNG1 & $2.02 \times 10^{21}$ & $2.15 \times 10^{-7}$ & $5.53 \times 10^{-9}$ & 1.20 & $2.29 \times 10^{-6}$ \\
CMNG2 & $2.73 \times 10^{21}$ & $2.65 \times 10^{-7}$ & $6.81 \times 10^{-9}$ & 1.17 & $4.35 \times 10^{-6}$ \\
CMNG3 & $3.02 \times 10^{21}$ & $2.71 \times 10^{-7}$ & $6.97 \times 10^{-9}$ & 1.13 & $8.00 \times 10^{-6}$ \\
\hline
\end{tabular}

* CPE: constant phase element.

\subsection{FTIR Results}

Figure 4 shows the FTIR spectra of the electrolytes at a wavenumber of $550-4000 \mathrm{~cm}^{-1}$. The bands due to -OH stretching and -OH bending can be found at (i) $3700-3150 \mathrm{~cm}^{-1}$ in a broad peak form and (iv) $1250-1500 \mathrm{~cm}^{-1}$ in a sharp peak form, respectively which caused by the addition of glycerol into the system [50,51]. Numerous peaks are observed in-band region (iv) where the one centered at $1332 \mathrm{~cm}^{-1}$ came from -OH bending. In addition, the observed peak ascribed to the $\mathrm{NH}_{4}{ }^{+}$asymmetry elucidates a high tendency of the $\mathrm{NH}_{4}{ }^{+}$ distortion to release $\mathrm{H}^{+}$ions [52]. Furthermore, the $-\mathrm{CH}$ symmetrical stretching and $-\mathrm{CH}$ asymmetrical stretching are found at the band region of (ii) 3050 to $2850 \mathrm{c} \mathrm{m}^{-1}[53,54]$. It is noticed that the intensity of the - $\mathrm{CH}$ bands is increased as the concentration of glycerol increases which signified the complex development between the glycerol and CS-MC$\mathrm{NH}_{4} \mathrm{NO}_{3}$ [55]. The location carboxamide and amine band for the electrolytes are located at (iii) $1750-1520 \mathrm{~cm}^{-1}$ where a slight shift is observed when the concentration of glycerol increases. The shift shows the effect of glycerol concentration to provide more ions for the interaction with the oxygen and nitrogen atoms in the polymer blend [56]. Aziz et al. [57] and Shukur et al. [58] also reported a similar range of carboxamide and amine bands for their electrolyte systems. Lastly, the sharp peak located at (v) $900-1200 \mathrm{~cm}^{-1}$ possibly belongs to the $\mathrm{C}-\mathrm{O}$ stretching which is comparable to the previous work reported by Mejenom et al. [59] and Poy et al. [60]. As the concentration of glycerol is increased, this band peak becomes sharper and causes a small shoulder peak to appear which also describes the interaction between the CS-MC- $\mathrm{NH}_{4} \mathrm{NO}_{3}$ and glycerol. 


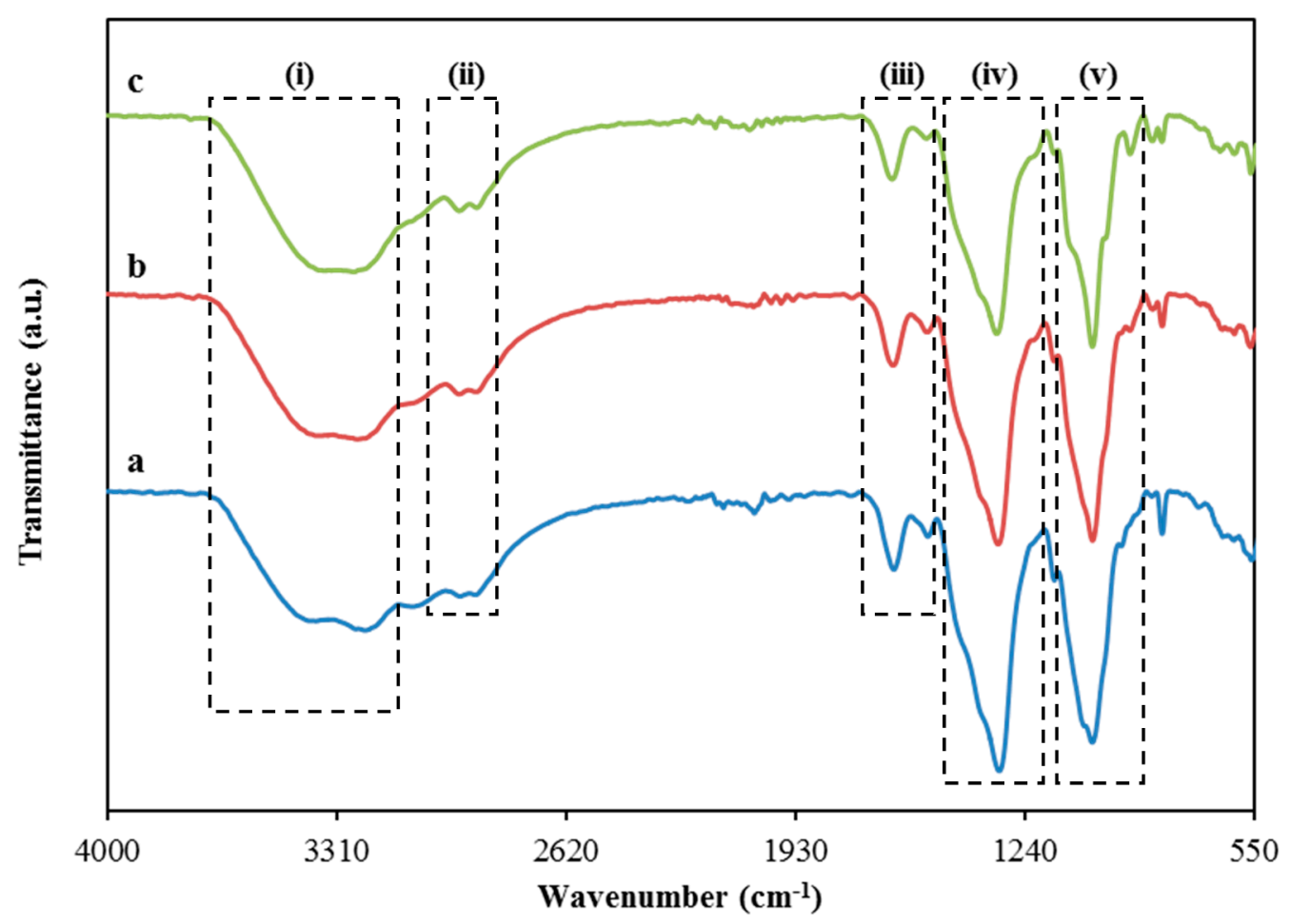

Figure 4. Fourier transform infrared spectroscopy (FTIR) spectra for (a) CMNG1, (b) CMNG2 and (c) CMNG3.

The FTIR deconvolution analysis is employed to support the ionic conductivity results where it also provides several advantageous properties such as resolving the overlapping peaks, removing noise and fringes from the spectrum, and inspecting the interconnection among deconvolution parameters [61]. Based on this approach, the deconvolution FTIR spectra can provide the fraction of conducting ions. The deconvolution possibility of FTIR spectra allowed one to isolate the existing peaks as well as alter both intensity and wavenumber as highlighted by Ramelli et al. [62]. Thus, the involvement of $\mathrm{H}^{+}$in charge carriers can be verified. The opted band region for the deconvolution purpose was from 1250 to $1500 \mathrm{~cm}^{-1}$, as shown in Figure 5. This is payable to the evident interaction as before clarified in the FTIR analysis. In the same band region, the use of $\mathrm{NH}_{4} \mathrm{NO}_{3}$ led to shift the bands within the range of $1200-1500 \mathrm{~cm}^{-1}$, as reported by Kamarudin and Isa [63] and Hafiza and Isa [64]. Thus, this approach is intended to isolate the free and ion pairs appropriately. The free ions correspond to the free mobile ions like $\mathrm{H}^{+}$while the ion pairs correspond to the ions of $\mathrm{NH}_{4}{ }^{+}$or $\mathrm{NO}_{3}{ }^{-}$[65-67]. With the help of the deconvoluted FTIR spectra shown in Figure 5, the percentage of free ions can be quantified using the following equation:

$$
\text { Free ions } \%=\frac{\text { Area of free ions peak }}{\text { Total area }(\text { free ions peak }+ \text { ions pair peak })} \times 100
$$



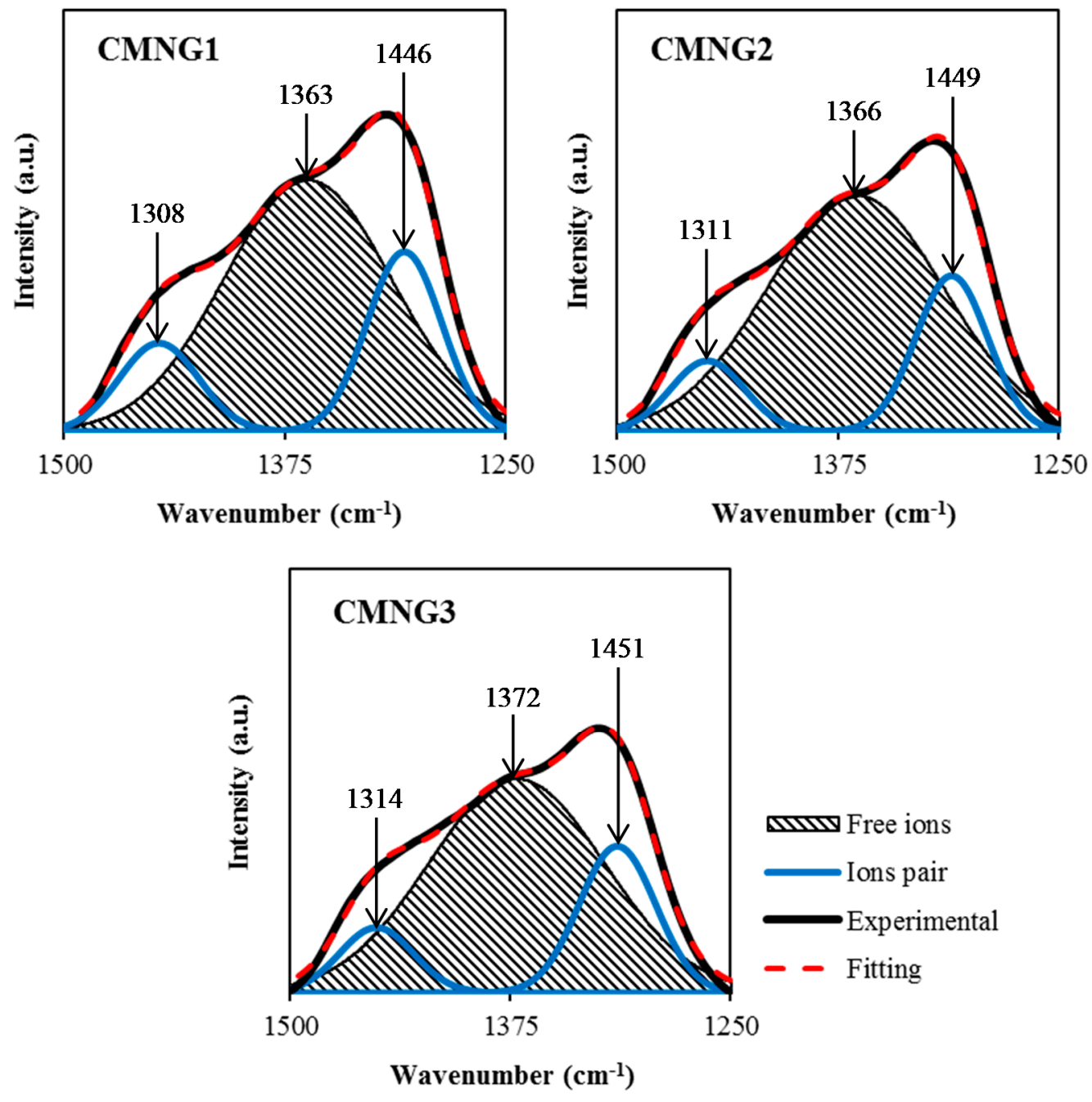

Figure 5. Deconvolution of FTIR spectra at $1250-1500 \mathrm{~cm}^{-1}$.

The percentage of free ions obtained by CMNG1 is $67.5 \%$, which then significantly increased to $71.7 \%$ with $28 \mathrm{wt}$. $\%$ of glycerol. However, a slight decrease of the free ions percentage to $70.2 \%$ is observed when the concentration of glycerol is increased to $42 \mathrm{wt} . \%$. This is generally explained that the percentage of free ions is influenced by the concentration of glycerol in the system which is highly correlated to the trend of the ionic conductivity. The increase of $\mathrm{H}^{+}$ions that dissociated from $\mathrm{NH}_{4}{ }^{+}$could also be a factor for the increment of ionic conductivity. Aniskari et al. [68] also reported the highest conducting electrolyte also had the highest percentage of free ions. By employing the percentage of free ions for each electrolyte, the transport parameters of number density $(n)$, ionic mobility $(\mu)$, and diffusion coefficient $(D)$, can be calculated using the Equations (16)-(18), where $N_{A}$ is Avogadro's constant, $M$ represents the number of moles of glycerol, and $e$ is the elementary charge. $V_{\text {Total }}$ is the total volume of the polymer electrolytes.

$$
\begin{gathered}
n=\frac{M \times N_{A}}{V_{\text {Total }}} \times(\text { free ion } \%) \\
\mu=\frac{\sigma}{n e} \\
D=\frac{\mu k T}{e}
\end{gathered}
$$


The calculated transport parameters of the electrolytes are listed in Table 3 using FTIR routine. It can be observed that the trend of number density is followed the ionic conductivity pattern as in Table 1 . The dissociation of $\mathrm{H}^{+}$ions assists to facilitate the coordination of the $\mathrm{H}^{+}$ions in the electrolyte system which leads to the enhancement of ionic conductivity value $[69,70]$. This can be further proved through the trend of $\mu$ and $D$. The flexibility and the segmental wave of the polymer chains in the system also predisposed the transport properties as well as the ionic conductivity [71]. However, the improvement of transport properties was observed when glycerol concentration reached $42 \mathrm{wt}$. \% which is due to the enhancement of the chain flexibility that leads to the concentration increment of $\mathrm{H}^{+}$carriers, and thus increases the ionic conductivity of the electrolyte.

Table 3. Transport parameters values of the electrolytes.

\begin{tabular}{cccc}
\hline Electrolyte & $\boldsymbol{n}\left(\mathbf{c m}^{-3}\right)$ & $\boldsymbol{\mu}\left(\mathbf{c m}^{\mathbf{2}} \mathbf{V}^{-\mathbf{1}} \mathbf{s}^{-\mathbf{1}}\right)$ & $\boldsymbol{D}\left(\mathbf{c m}^{\mathbf{2}} \mathbf{s}^{-\mathbf{1}}\right)$ \\
\hline CMNG1 & $4.90 \times 10^{22}$ & $1.02 \times 10^{-8}$ & $2.67 \times 10^{-10}$ \\
CMNG2 & $6.31 \times 10^{22}$ & $1.11 \times 10^{-8}$ & $2.87 \times 10^{-10}$ \\
CMNG3 & $6.80 \times 10^{22}$ & $1.14 \times 10^{-8}$ & $2.98 \times 10^{-10}$ \\
\hline
\end{tabular}

\subsection{Transference Number Study}

The transfer of electrons and ions in an electrolyte provides conductivity. In order to determine the primary charge carrier, transference number (TNM) was evaluated at an applied voltage of $0.2 \mathrm{~V}$. Figure 6 depicts polarization of the highest conductivity for the CS:MC: $\mathrm{NH}_{4} \mathrm{NO}_{3}$ :glycerol system. It is obvious that at the beginning of the polarization process, the conduction of ions and electrons results in a significant current of $1.5 \mu \mathrm{A}$. As already mentioned, the evaluation is based on the SS electrode, owing to blocking the ions and permitting the electrons to pass. Therefore, as the time increases, the current minimizes up to a plateau at $0.1 \mu \mathrm{A}$. This steady-state current indicates the occurrence of a polarization process of the electrolyte. Thus, cations and anions are adsorbed at the negative electrode and the positive electrode, respectively [72,73]. At this stage, the current is only carried by electrons. The $t_{e}$ value of 0.07 and the $t_{i}$ value of 0.93 were obtained. Since $t_{i}$ is higher than $t_{e}$, the dominant charge carriers of CS:MC: $\mathrm{NH}_{4} \mathrm{NO}_{3}$ :glycerol electrolyte are the ions [74]. The accumulation of these ions on the surface electrodes allows EDLC applications. For the ammonium salt-based SPE reported by Vijaya et al. [75], the $t_{i}$ values were in the range of 0.90 to 0.99 . Samsi et al. [76] obtained the $t_{i}$ value of 0.916 for cellulose acetate (75 wt.\%)- $\mathrm{NH}_{4} \mathrm{I}(25 \mathrm{wt} . \%)$ system. In another work, the ions are also dominated (i.e., 0.85 out of 1 ) in ammonium based-poly(ethyl methacrylate) system [77]. Alia et al. [78] revealed the $t_{i}$ value of 0.905 for SPE of proton-based biopolymer with polycarbonate electrolyte as the plasticizer and zinc sulfate as the filler.

\subsection{LSV Study}

EDLC is known as a high cycle supercapacitor, thus it is crucial to investigate the working voltage range, frequently referred to as potential stability [79]. The study employed LSV, facilitated by SS electrodes, to identify the potential stability of every polymer electrolyte, and Figure 7 illustrates a normal LSV graph for the highest conducting CS:MC: $\mathrm{NH}_{4} \mathrm{NO}_{3}$ :glycerol blend electrolyte. The finding indicates that, from the EDLC application viewpoint [80], the potential stability is in the satisfactory working voltage range of $1.87 \mathrm{~V}$. According to Monisha et al. [81], the threshold voltage is that the current passes through the cells. The potential stability obtained for this work is comparable to other reports with ammonium salts as the ionic provider. A complexation of ethylene carbonate, $\mathrm{NH}_{4} \mathrm{NO}_{3}$, and $\mathrm{CS}$ yield potential stability of $1.8 \mathrm{~V}$ [82]. A system of $\mathrm{MC}: \mathrm{NH}_{4} \mathrm{Br}$ is reported to decompose beyond $1.53 \mathrm{~V}$ [19]. In another report, poly ( $\varepsilon$-caprolactone) (PCL)-based polymer electrolytes are stable up to $1.4 \mathrm{~V}$ as ammonium thiocyanate is added [83]. 


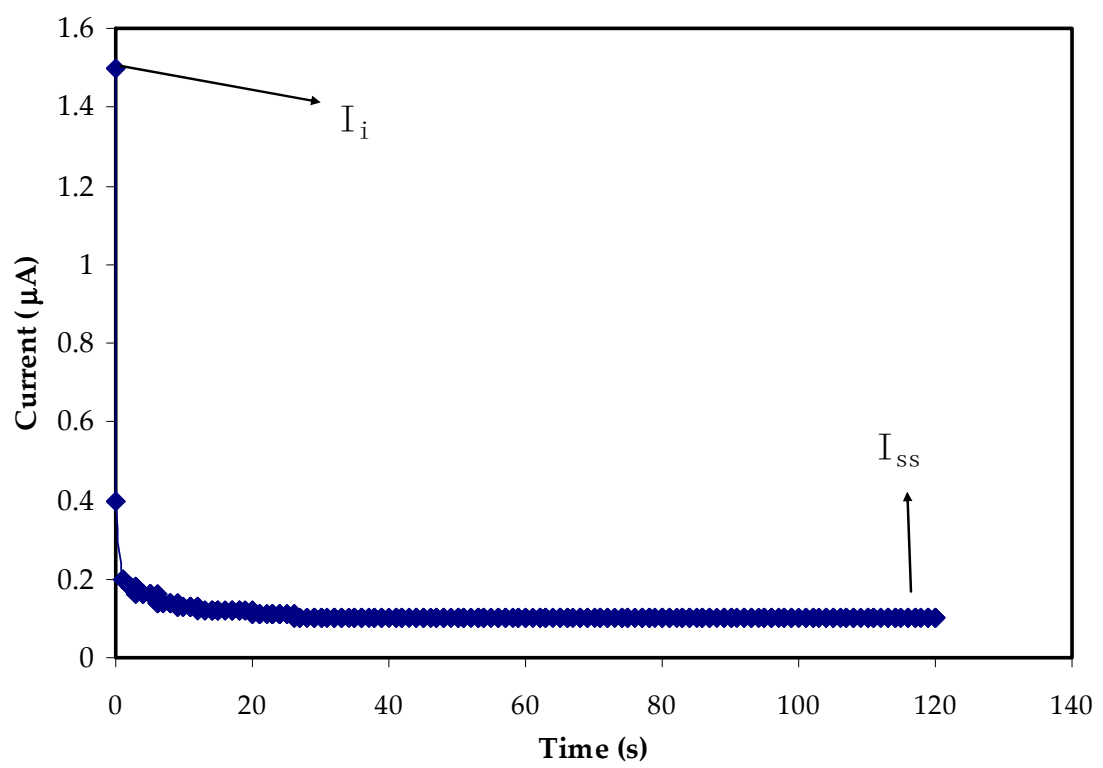

Figure 6. Polarization of the highest conducting electrolyte at $0.2 \mathrm{~V}$.

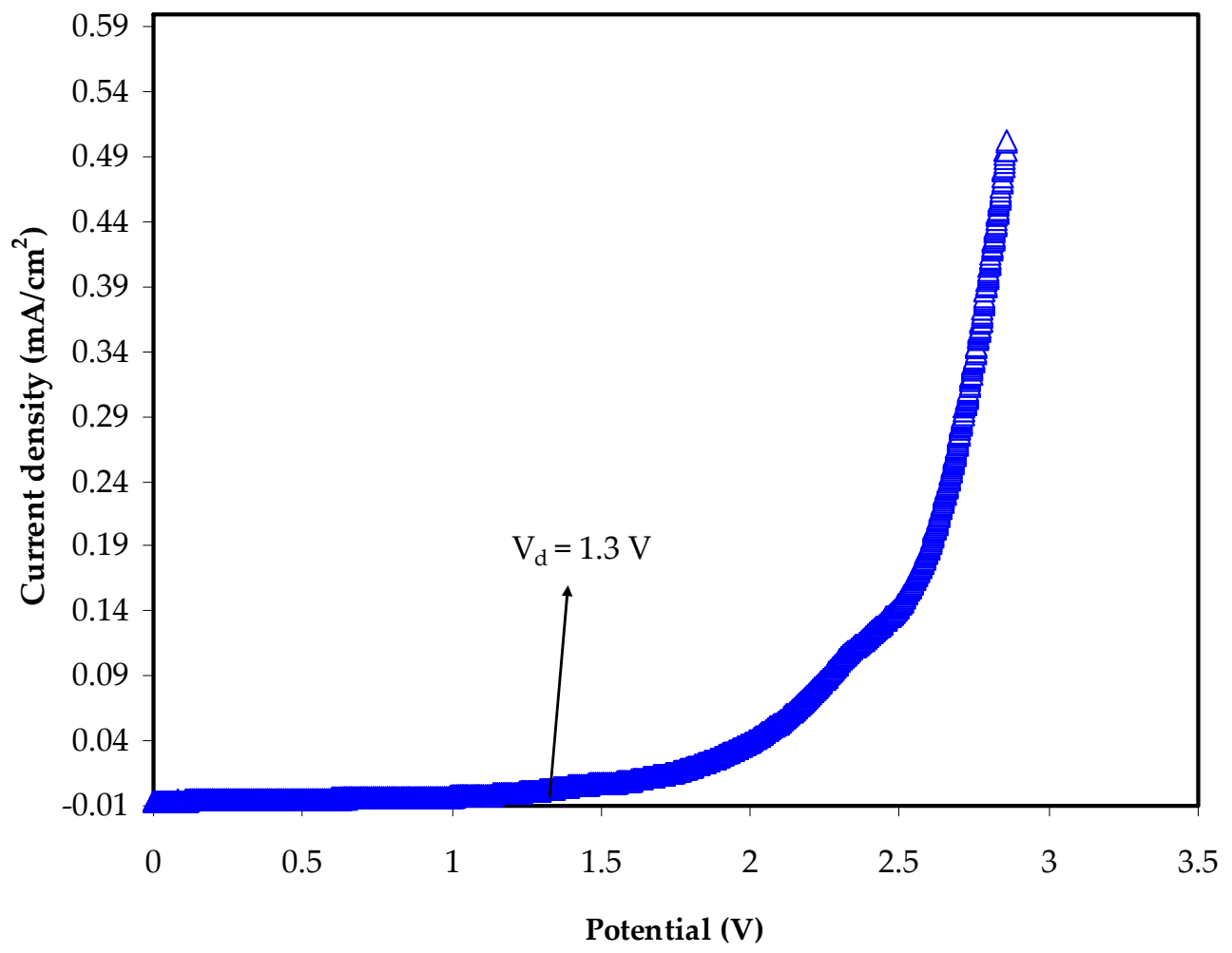

Figure 7. Linear Sweep Voltammetry (LSV) graph of the highest conducting electrolyte at $0.02 \mathrm{~V} / \mathrm{s}$.

\subsection{Charge-Discharge Study}

Figure 8 shows the charge-discharge cycle of the fabricated EDLC. An ideal capacitor will show a triangle curve due to polarization. Unlike conventional batteries where the discharge curve is non-linear due to the process of inter-and de-intercalation. Figure 9 shows the $V_{d}$ and ESR of the EDLC in this work. $V_{d}$ is energy loss and highly dependent on the internal resistance. $V_{d}$ can be observed before every discharging process where the calculated average value is $0.0631 \mathrm{~V}$. The value of $V_{d}$ throughout the 500 cycles is quite stable at 125 th and 475 th cycles. This could be due to changes in ionic transportation 
pattern and the formation of the charge-double layer is disturbed. In addition to that, the ESR is also stable up to 500 cycles with an average of $63.1 \mathrm{ohms}$. A low value of ESR indicates that the constituents of EDLC have an excellent contact.

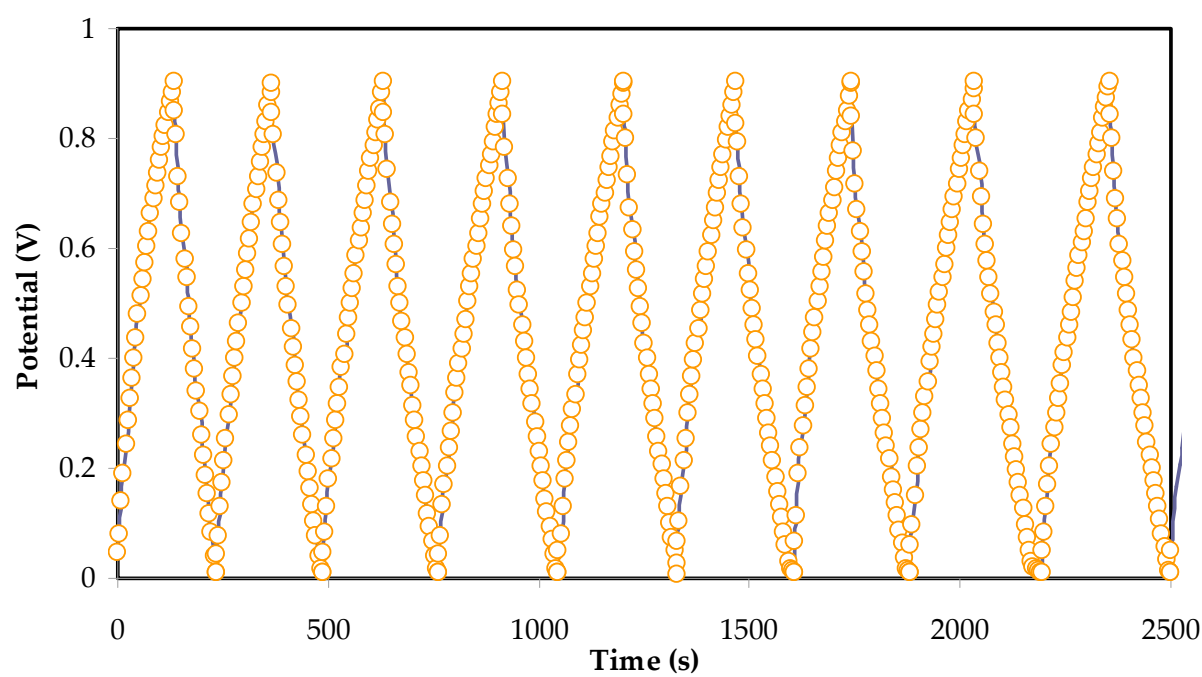

Figure 8. Selected charge-discharge graphs of the EDLC at $0.5 \mathrm{~mA} / \mathrm{cm}^{2}$.

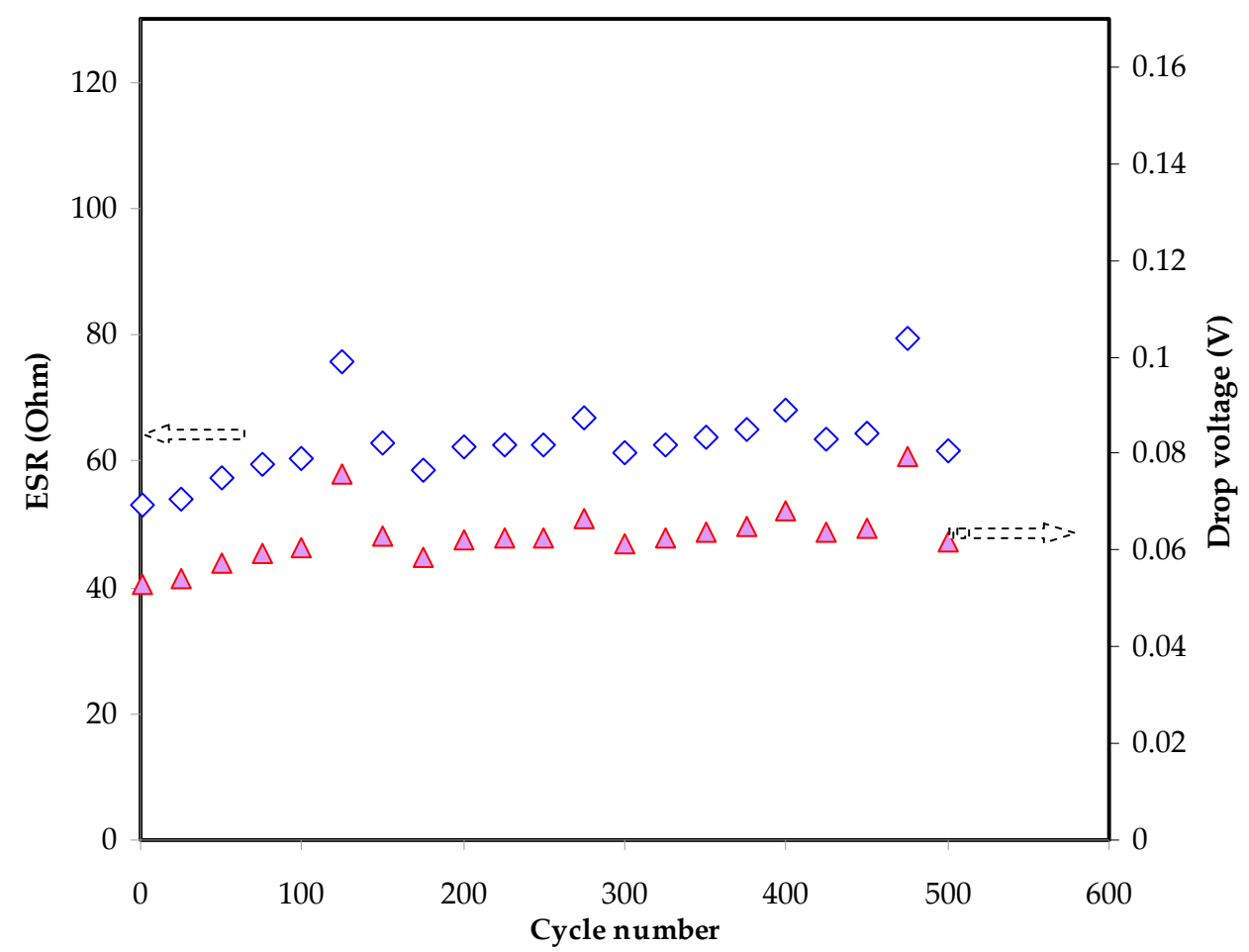

Figure 9. Equivalent series resistance (ESR) and drop voltage of the EDLC for 500 cycles of charging and discharging.

Figure 10 illustrates the $C_{S}$ and efficiency as a function of cycle number for the fabricated EDLC at $0.5 \mathrm{~mA} / \mathrm{cm}^{2}$. The $C_{s}$ value increases from $50.2 \mathrm{~F} / \mathrm{g}$ at the 1 st cycle to $68 \mathrm{~F} / \mathrm{g}$ at the 150th cycle, followed by almost unchanging value after the 175th cycle upwards and reached an average value of $75 \mathrm{~F} / \mathrm{g}$ when 500 cycles are completed. A rapid build-up of the double layers in EDLCs/supercapacitors is a main reason that the capacitance value is relatively low at the 1 st cycle. 


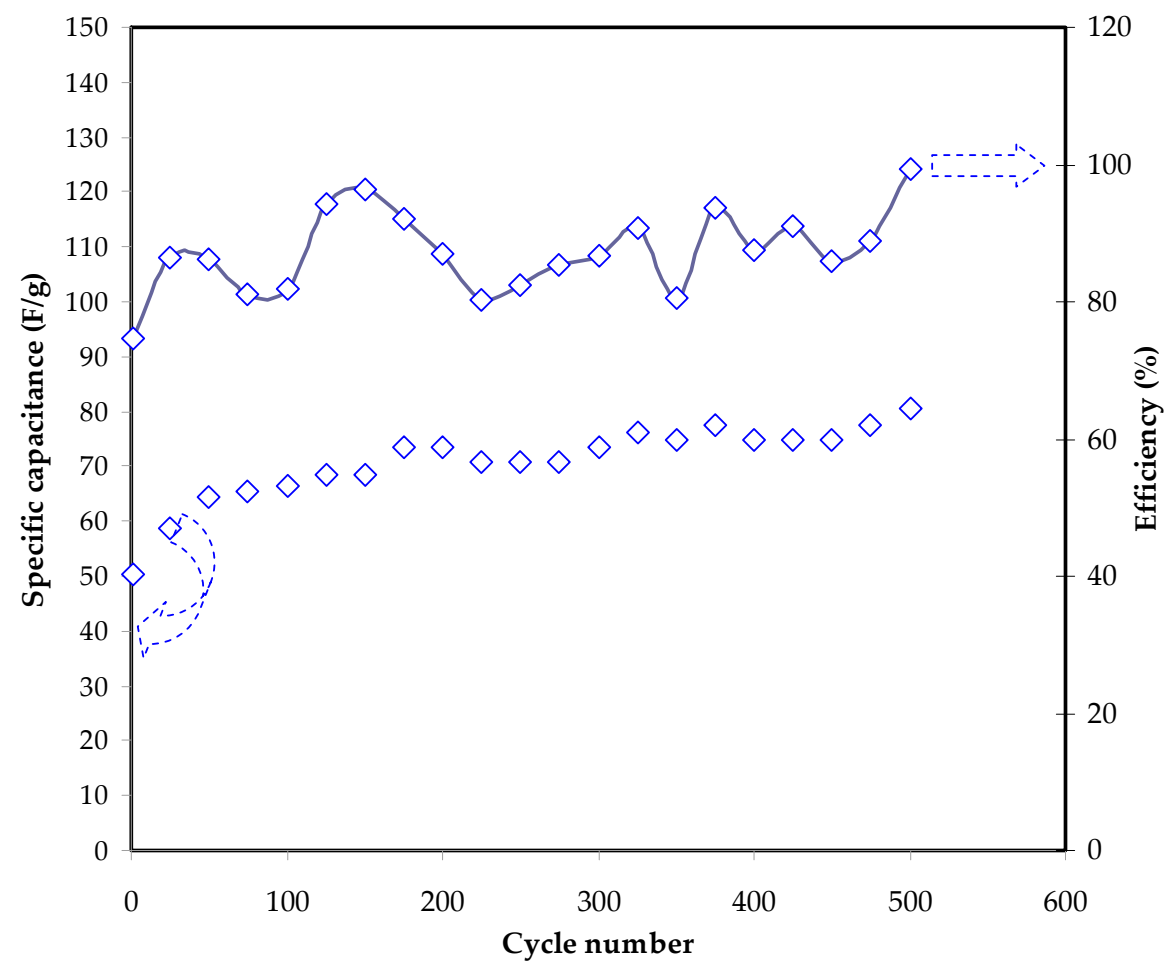

Figure 10. $C_{s}$ and efficiency of the EDLC against the cycle number at $0.5 \mathrm{~mA} / \mathrm{cm}^{2}$.

Negatively and positively charged ions are still employed to get used to the conduction pattern at the initial stage $[84,85]$. Table 4 shows an example of reported works related to the application of EDLC using various types of polymer electrolytes and materials. Many aspects have to be considered such as salts, polymer, filler, plasticizer, and electrodes used.

Table 4. Various types of electrochemical double-layer capacitor (EDLC) with their relative electrodes and specific capacitance value.

\begin{tabular}{|c|c|c|c|}
\hline System & Active Materials & $C(\mathrm{~F} / \mathrm{g})$ & Reference \\
\hline $\begin{array}{l}\text { hydroxylethyl cellulose }+\mathrm{MgTf}_{2}+ \\
\text { EMIMT + silica nanoparticles }\end{array}$ & Activated carbon & 25.1 & [1] \\
\hline $\mathrm{PVA}+\mathrm{CH}_{3} \mathrm{COONH}_{4}+\mathrm{BmImCl}$ & Activated carbon & 31.3 & [86] \\
\hline $\mathrm{MC}+\mathrm{NH}_{4} \mathrm{NO}_{3}+\mathrm{PEG}$ & PEG/Activated carbon & 38.0 & [87] \\
\hline PVA/polystyrene & Carbon & 40.0 & [88] \\
\hline Cellulose $+\mathrm{Na}_{2} \mathrm{SO}_{4}$ & Cellulose nanofiber + graphite & 43.0 & [89] \\
\hline $\mathrm{CS}+\mathrm{MC}+\mathrm{NH}_{4} \mathrm{NO}_{3}+$ glycerol & Activated carbon & 50.2 & Present work \\
\hline
\end{tabular}

The efficiency of the EDLC is illustrated in Figure 10. The high value of efficiency signifies that the discharging part is equal to or longer than the charging time. The efficiency of $74 \%$ can be observed at the first cycle. Usually, the charging process lasts longer in comparison with discharging. By subjecting the current, cations and anions begin approaching the electrode and become familiar with the conduction trend. A low efficiency is given at this stage. The efficiency is varied in the range of $80-99 \%$. These findings of the present work reveal that the EDLC possesses good cycling stability and contact as well as less charge drop up to 500 cycles.

Figure 11 depicts the variation of $E$ and $P$ over 500 cycles, respectively. The $E$ value was found to be $6.79 \mathrm{Wh} / \mathrm{kg}$ at the first cycle and then reached $9.52 \mathrm{Wh} / \mathrm{kg}$. Beyond 175 cycles, E is clearly started to stabilize at an average value of $10.38 \mathrm{Wh} / \mathrm{kg}$ all over the 500 charge-discharge cycles. This fact clarifies that both $\mathrm{NO}_{3}{ }^{-}$anions and $\mathrm{NH}_{4}{ }^{+}$or $\mathrm{H}^{+}$ cations in the polymer chains of the CS:MC blend move towards the electrode surface at an almost similar energy barrier [90]. Winie et al. [91], demonstrated that a CS-based 
EDLC has energy density from 0.57 to $2.8 \mathrm{Wh} / \mathrm{kg}$ as the current density changes from 2 to $0.6 \mathrm{~mA} / \mathrm{cm}^{2}$, respectively. The low ion aggregation is due to stability in energy density and capacitance pattern. The EDLC shows a higher power density than batteries owing to the absence of the intercalation/deintercalation process in the former one. This needs more energy and a longer distance for ions to move back to the electrolyte. $P$ value at the 1st cycle was found to be $1941 \mathrm{~W} / \mathrm{kg}$ and minimized to $1633 \mathrm{~W} / \mathrm{kg}$ at the 150 th cycle. Yassine et al. [92], mentioned that the power density is largely linked to internal resistance; therefore, the $P$ pattern will be opposed to the ESR pattern. An increase in the ESR value leads to a drop in the value of $P$. After the 175th cycle, the $P$ pattern remained almost unchanged with an average value of $1642 \mathrm{~W} / \mathrm{kg}$.

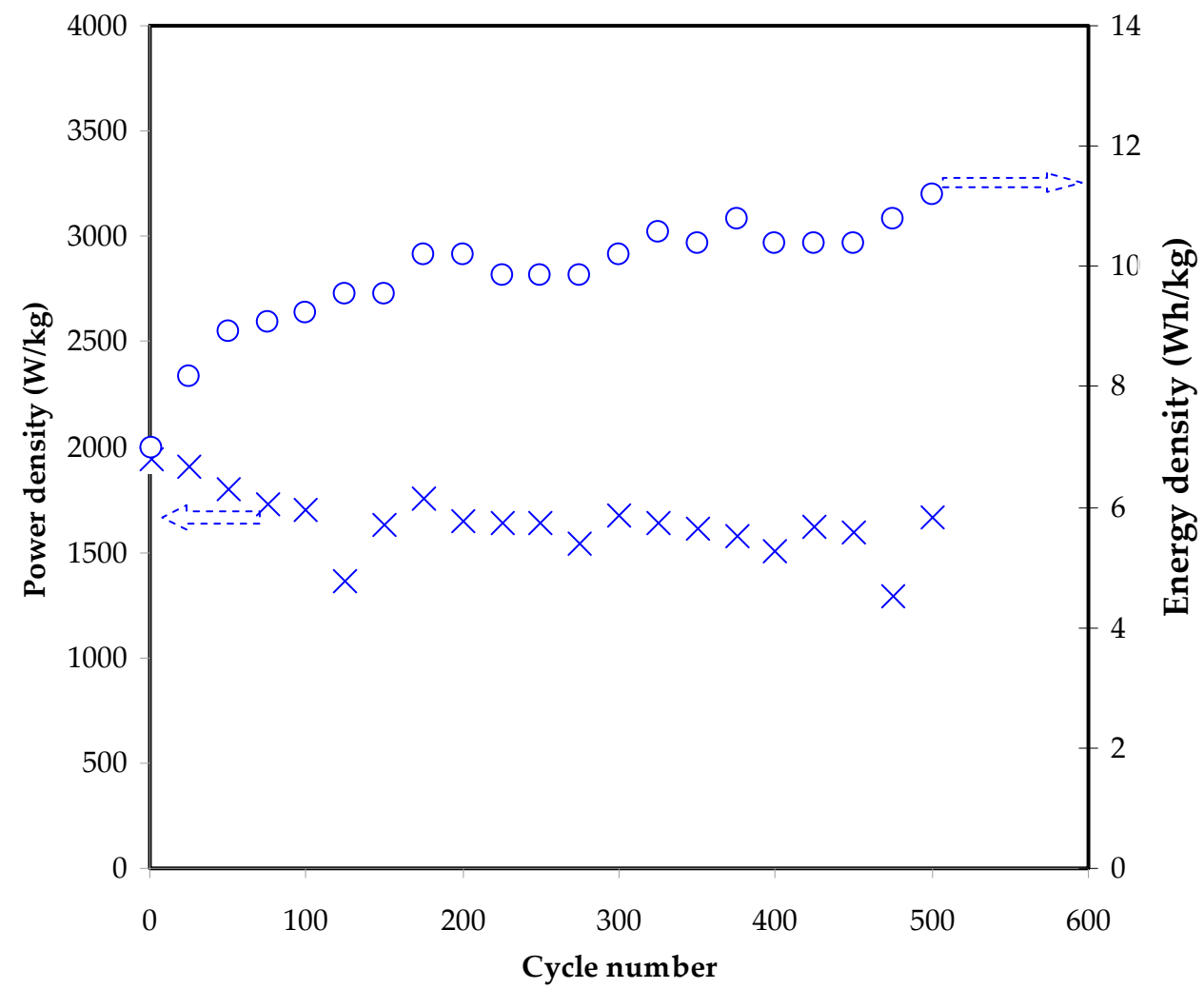

Figure 11. The plot of $E$ and $P$ of the EDLC versus the cycle number at $0.5 \mathrm{~mA} / \mathrm{cm}^{2}$.

\section{Conclusions}

In conclusion, structural, impedance, ion transport parameters, and device performances of the prepared electrolyte have been examined. The transport parameters and DC conductivity estimated from the EIS study reveals the suitability of the electrolyte for device fabrication. The FTIR results and their significant deconvolution were used to detect the interaction that occurs among polymer electrolyte components and determine the transport parameters. The transport properties completed from FTIR analysis is close enough to that achieved from EIS data. The dominant role of ion to the total conductivity was proven from transference number measurement (TNM) as the ionic was found to be 0.93 . CS-MC- $\mathrm{NH}_{4} \mathrm{NO}_{3}$-glycerol electrolyte was potentially stable up to $1.87 \mathrm{~V}$. The EDLC was tested for 500 complete charge-discharge cycles. The specific capacitance has a pattern that is similar to that of the energy density as both of them are quite related and the values are stabilized beyond 175th cycles. The specific capacitance and energy density of the EDLC at the first cycle are $50.2 \mathrm{~F} / \mathrm{g}$ and $6.97 \mathrm{Wh} / \mathrm{kg}$, respectively. Meanwhile, the internal resistance and power density of the EDLC have a similar trend. The average power density and internal resistance of the EDLC throughout the 500 cycles are $1642 \mathrm{~W} / \mathrm{kg}$ 
and 63.14 ohms, respectively. The performance of the EDLC can be improved by other researchers via the modifications of electrodes and electrolytes.

Author Contributions: S.B.A., W.O.K. and M.F.Z.A.K.; Formal analysis, M.H.H., M.M.N. and A.S.F.M.A.; Funding acquisition, E.M.A.D.; Investigation, M.H.H.; Project administration, S.B.A. and M.F.Z.A.K.; Validation, S.B.A., E.M.A.D., H.O.G., M.M.N., W.O.K., A.S.F.M.A., J.M.H. and M.F.Z.A.K.; Visualization, W.O.K.; Writing-original draft, S.B.A.; Writing—review \& editing, E.M.A.D., M.H.H., H.O.G., M.M.N., W.O.K., A.S.F.M.A., J.M.H. and M.F.Z.A.K. All authors have read and agreed to the published version of the manuscript.

Funding: This research received no external funding.

Data Availability Statement: Data will be made available at request.

Acknowledgments: We would like to acknowledge all support for this work by the University of Sulaimani, Prince Sultan University and Komar University of Science and Technology. The authors would like to acknowledge the support of Prince Sultan University for paying the Article Processing Charges (APC) of this publication and for their financial support.

Conflicts of Interest: The authors declare no conflict of interest.

\section{References}

1. Chong, M.Y.; Numan, A.; Liew, C.-W.; Ng, H.M.; Ramesh, K.; Ramesh, S. Enhancing the performance of green solid-state elec-tric double-layer capacitor incorporated with fumed silica nanoparticles. J. Phys. Chem. Solids 2018, 117, 194-203. [CrossRef]

2. Ramaswamy, M.; Malayandi, T.; Selvasekarapandian, S.; Srinivasalu, J.; Rangaswamy, M.; Soundararajan, V. Development and study of solid polymer electrolyte based on polyvinyl alcohol: $\mathrm{Mg}\left(\mathrm{ClO}_{4}\right)_{2}$. Polym.-Plast. Technol. Eng. 2017, 56, 992-1002. [CrossRef]

3. Mustafa, M.S.; Ghareeb, H.O.; Aziz, S.B.; Brza, M.A.; Al-Zangana, S.; Hadi, J.M.; Kadir, M.F.Z. Electrochemical Characteristics of Glycerolized PEO-Based Polymer Electrolytes. Membranes 2020, 10, 116. [CrossRef]

4. Asnawi, A.S.F.M.; Hamsan, M.H.; Aziz, S.B.; Kadir, M.F.Z.; Matmin, J.; Yusof, Y.M. Impregnation of [Emim] Br ionic liquid as plasticizer in biopolymer electrolytes for EDLC application. Electrochim. Acta 2021, 375, 137923. [CrossRef]

5. Mazhandu, Z.S.; Muzenda, E.; Mamvura, T.A.; Belaid, M.; Nhubu, T. Integrated and Consolidated Review of Plastic Waste Management and Bio-Based Biodegradable Plastics: Challenges and Opportunities. Sustainability 2020, 12, 8360. [CrossRef]

6. Misenan, M.S.M.; Isa, M.I.N.; Khiar, A.S.A. Electrical and structural studies of polymer electrolyte based on chi-tosan/methyl cellulose blend doped with BMIMTFSI. Mater. Res. Express 2018, 5, 5. [CrossRef]

7. Hadi, J.M.; Aziz, S.B.; Nofal, M.M.; Hussein, S.A.; Hamsan, M.H.; Brza, M.A.; Abdulwahid, R.T.; Kadir, M.F.Z.; Woo, H.J. Electrical, Dielectric Property and Electrochemical Performances of Plasticized Silver Ion-Conducting Chitosan-Based Polymer Nanocomposites. Membranes 2020, 10, 151. [CrossRef] [PubMed]

8. Taghizadeh, M.T.; Seifi-Aghjekohal, P. Sonocatalytic degradation of 2-hydroxyethyl cellulose in the presence of some nanoparticles. Ultrason. Sonochem. 2015, 26, 265-272. [CrossRef] [PubMed]

9. Singh, P.; Bharati, C.D.; Gupta, P.N.; Saroj, A.L. Vibrational, thermal and ion transport properties of PVA-PVP-PEG-MeSO 4 Na based polymer blend electrolyte films. J. Non-Cryst. Solids 2018, 494, 21-30. [CrossRef]

10. Prajapati, G.; Roshan, R.; Gupta, P. Effect of plasticizer on ionic transport and dielectric properties of $\mathrm{PVA}_{-} \mathrm{H}_{3} \mathrm{PO}_{4}$ proton conducting polymeric electrolytes. J. Phys. Chem. Solids 2010, 71, 1717-1723. [CrossRef]

11. Gao, H.; Lian, K. Proton-conducting polymer electrolytes and their applications in solid supercapacitors: A review. Royal Soc. Chem. 2014, 4, 33091-33113. [CrossRef]

12. Hadi, J.M.; Aziz, S.B.; Mustafa, M.S.; Brza, M.A.; Hamsan, M.H.; Kadir, M.F.Z.; Ghareeb, H.O.; Hussein, S.A. Electrochemical Impedance study of Proton Conducting Polymer Electrolytes based on PVC Doped with Thiocyanate and Plasticized with Glycerol. Int. J. Electrochem. Sci. 2020, 15, 4671-4683. [CrossRef]

13. Kadir, M.F.Z. Characteristics of Proton Conducting PVA-Chitosan Polymer Blend Electrolytes. Ph.D. Thesis, Univeristy of Malaya, Kuala Lumpur, Malaysia, 2010. Available online: http:/ / studentsrepo.um.edu.my/2744/ (accessed on 26 January 2021).

14. Iro, Z.S.; Subramani, C.; Dash, S.S. A Brief Review on Electrode Materials for Supercapacitor. Int. J. Electrochem. Sci. 2016, 11, 10628-10643. [CrossRef]

15. Inagaki, M.; Konno, H.; Tanaike, O. Carbon materials for electrochemical capacitors. J. Power Sources 2010, 195, 7880-7903. [CrossRef]

16. Zhang, D.; Zhang, X.; Chen, Y.; Yu, P.; Wang, C.; Ma, Y. Enhanced capacitance and rate capability of gra-phene/polypyrrole composite as electrode material for supercapacitors. J. Power Sources 2011, 196, 5990-5996. [CrossRef]

17. Pell, W.G.; Conway, B.E. Peculiarities and requirements of asymmetric capacitor devices based on combination of capacitor and battery-type electrodes. J. Power Sources 2004, 136, 334-345. [CrossRef] 
18. Aziz, S.B.; Brza, M.A.; Hamsan, E.M.A.D.M.H.; Hadi, J.M.; Kadir, M.F.Z.; Abdulwahid, R.T. The Study of Electrical and Electrochemical Properties of Magnesium Ion Conducting CS: PVA Based Polymer Blend Electrolytes: Role of Lattice Energy of Magnesium Salts on EDLC Performance. Molecules 2020, 25, 4503. [CrossRef] [PubMed]

19. Kadir, M.F.Z.; Salleh, N.S.; Hamsan, M.H.; Aspanut, Z.; Majid, N.A.; Shukur, M.F. Biopolymeric electrolyte based on glycerolized methyl cellulose with NH4Br as proton source and potential application in EDLC. Ionics 2017, 24, 1651-1662. [CrossRef]

20. Kamarudin, K.H.; Hassan, M.; Isa, M.I.N. Lightweight and Flexible Solid-State EDLC based on Optimized $\mathrm{CMC}^{-\mathrm{NH}_{4}} \mathrm{NO}_{3}$ Solid Bio-Polymer Electrolyte. ASM Sci. J. 2018, 1, 29-36.

21. Wang, C.; Liu, T. Nori-based N, O, S, Cl co-doped carbon materials by chemical activation of $\mathrm{ZnCl}_{2}$ for supercapacitor. J. Alloys Compd. 2017, 696, 42-50. [CrossRef]

22. Lee, D.-Y.; An, G.-H.; Ahn, H.-J. High-surface-area tofu based activated porous carbon for electrical double-layer capaci-tors. J. Ind. Eng. Chem. 2017, 52, 121-127. [CrossRef]

23. Arof, A.K.; Kufian, M.Z.; Syukur, M.F.; Aziz, M.F.; Abdelrahman, A.E.; Majid, S.R. Electrical double layer capacitor using poly(methyl methacrylate)-C4BO8Li gel polymer electrolyte and carbonaceous material from shells of matakucing (Dimocarpuslongan) fruit. Electrochim. Acta 2012, 74, 39-45. [CrossRef]

24. Zhou, P.-W.; Li, B.-H.; Kang, F.-Y.; Zeng, Y.-Q. The development of supercapacitors from coconut-shell activated carbon. New Carbon Mater. 2006, 21, 125-131.

25. Wang, H.; Lin, J.; Shen, Z.X. Polyaniline (PANi) based electrode materials for energy storage and conversion. J. Sci. Adv. Mater. Devices 2016, 1, 225-255. [CrossRef]

26. Sequeira, C.A.; Plancha, M.J.; Araújo, L.P. Conductivity studies on solid polymer electrolytes. J. Phys. Colloq. 1994, 4, janvier1994. [CrossRef]

27. Miguel, E.R.D.S.; Aguilar, J.C.; De Gyves, J. Structural effects on metal ion migration across polymer inclusion membranes: Dependence of transport profiles on nature of active plasticizer. J. Membr. Sci. 2008, 307, 105-116. [CrossRef]

28. Hamsan, M.H.; Aziz, S.B.; Nofal, M.M.; Brza, M.A.; Abdulwahid, R.T.; Hadi, J.M.; Karim, W.O.; Kadir, M.F.Z. Characteristics of EDLC device fabricated from plasticized chitosan: $\mathrm{MgCl}_{2}$ based polymer electrolyte. J. Mater. Res. Technol. 2020, 9, 10635-10646. [CrossRef]

29. Hadi, J.M.; Aziz, S.B.; Mustafa, M.S.; Hamsan, M.H.; Abdulwahid, R.T.; Kadir, M.F.Z.; Ghareeb, H.O. Role of nano-capacitor on dielectric constant enhancement in PEO:NH4SCN:xCeO 2 polymer nano-composites: Electrical and electrochemical properties. J. Mater. Res. Technol. 2020, 9, 9283-9294. [CrossRef]

30. Polu, A.R.; Kumar, R. AC impedance and dielectric spectroscopic studies of $\mathrm{Mg}^{2+}$ ion conducting PVA-PEG blended polymer electrolytes. Bull. Mater. Sci. 2011, 34, 1063-1067. [CrossRef]

31. Aziz, S.B.; Hamsan, M.H.; Brza, M.A.; Kadir, M.F.Z.; Muzakir, S.K.; Abdulwahid, R.T. Effect of glycerol on EDLC characteristics of chitosan:methylcellulose polymer blend electrolytes. J. Mater. Res. Technol. 2020, 9, 8355-8366. [CrossRef]

32. Zhang, S.; Yang, L.; Liu, Q. Impedance study on the interface of polyelectrolyte and metal sodium. Solid State Ionics 1995, 76, 127-132. [CrossRef]

33. Aziz, S.B.; Abdullah, O.G.; Rasheed, M.A.; Ahmed, H.M. Effect of High Salt Concentration (HSC) on Structural, Morphological, and Electrical Characteristics of Chitosan Based Solid Polymer Electrolytes. Polymers 2017, 9, 187. [CrossRef] [PubMed]

34. Zulkifli, A.M. Electrochemical Characteristics of Phthaloyl Chitosan Based Gel Polymer Electrolyte for Dye Sensitized Solar Cell Application. Int. J. Electrochem. Sci. 2020, 15, 7434-7447. [CrossRef]

35. Aziz, S.B.; Abidin, Z.H.Z.; Arof, A.K. Influence of silver ion reduction on electrical modulus parameters of solid polymer electrolyte based on chitosan-silver triflate electrolyte membrane. Express Polym. Lett. 2010, 4, 300-310. [CrossRef]

36. Zulkifli, A.M.; Said, N.I.A.M.; Aziz, S.B.; Dannoun, E.M.A.; Hisham, S.; Shah, S.; Abu Bakar, A.; Zainal, Z.H.; Tajuddin, H.A.; Hadi, J.M.; et al. Characteristics of Dye-Sensitized Solar Cell Assembled from Modified Chitosan-Based Gel Polymer Electrolytes Incorporated with Potassium Iodide. Molecules 2020, 25, 4115. [CrossRef]

37. Aziz, S.B.; Abdullah, R.M.; Rasheed, M.A.; Ahmed, H.M. Role of Ion Dissociation on DC Conductivity and Silver Nanoparticle Formation in PVA: AgNt Based Polymer Electrolytes: Deep Insights to Ion Transport Mechanism. Polymers 2017, 9, 338. [CrossRef]

38. Aziz, S.B.; Hamsan, M.H.; Abdullah, R.M.; Abdulwahid, R.T.; Brza, M.A.; Marif, A.S.; Kadir, M.F.Z. Protonic EDLC cell based on chitosan (CS): Methylcellulose (MC) solid polymer blend electrolytes. Ionics 2020, 26, 1829-1840. [CrossRef]

39. Aziz, S.B.; Abdullah, R.M. Crystalline and amorphous phase identification from the tan $\delta$ relaxation peaks and impedance plots in polymer blend electrolytes based on [CS:AgNt]x:PEO(x-1) $(10 \leq x \leq 50)$. Electrochim. Acta 2018, 285, 30-46. [CrossRef]

40. Teo, L.P.; Buraidah, M.H.; Nor, A.F.M.; Majid, S.R. Conductivity and dielectric studies of $\mathrm{Li}_{2} \mathrm{SnO}_{3}$. Ionics 2012, 18, 655-665. [CrossRef]

41. Aziz, S.B.; Woo, T.J.; Kadir, M.; Ahmed, H.M. A conceptual review on polymer electrolytes and ion transport models. J. Sci. Adv. Mater. Devices 2018, 3, 1-17. [CrossRef]

42. Aziz, S.B.; Hamsan, M.H.; Abdullah, R.M.; Kadir, M.F.Z. A Promising Polymer Blend Electrolytes Based on Chitosan: Methyl Cellulose for EDLC Application with High Specific Capacitance and Energy Density. Molecules 2019, 24, 2503. [CrossRef] [PubMed]

43. Aziz, S.B.; Marif, R.B.; Brza, M.A.; Hamsan, M.H.; Kadir, M.F.Z. Employing of Trukhan Model to Estimate Ion Transport Parameters in PVA Based Solid Polymer Electrolyte. Polymers 2019, 11, 1694. [CrossRef] [PubMed] 
44. Awasthi, P.; Das, S. Reduced electrode polarization at electrode and analyte interface in impedance spectroscopy using carbon paste and paper. Rev. Sci. Instrum. 2019, 90, 124103. [CrossRef]

45. Yahya, M.; Arof, A. Effect of oleic acid plasticizer on chitosan-lithium acetate solid polymer electrolytes. Eur. Polym. J. 2003, 39, 897-902. [CrossRef]

46. Aziz, S.B.; Abidin, Z.H.Z. Ion-transport study in nanocomposite solid polymer electrolytes based on chitosan: Electrical and dielectric analysis. J. Appl. Polym. Sci. 2015, 132, 1-10. [CrossRef]

47. Samsudin, A.S.; Isa, M.I.N. Characterization of carboxy methylcellulose doped with DTAB as new types of biopolymer electrolytes. Bull. Mater. Sci. 2012, 35, 1123-1131. [CrossRef]

48. Brza, M.; Aziz, S.; Anuar, H.; Ali, F. Structural, ion transport parameter and electrochemical properties of plasticized polymer composite electrolyte based on PVA: A novel approach to fabricate high performance EDLC devices. Polym. Test. 2020, $91,106813$. [CrossRef]

49. Brza, M.A.; Aziz, S.B.; Anuar, H.; Dannoun, E.M.A.; Ali, F.; Abdulwahid, R.T.; Al-Zangana, S.; Kadir, M.F. The Study of EDLC Device with High Electrochemical Performance Fabricated from Proton Ion Conducting PVA-Based Polymer Composite Electrolytes Plasticized with Glycerol. Polymers 2020, 12, 1896. [CrossRef] [PubMed]

50. Aziz, S.B.; Marif, R.B.; Brza, M.A.; Hassan, A.N.; Ahmad, H.A.; Faidhalla, Y.A.; Kadir, M.F.Z. Structural, thermal, morphological and optical properties of PEO filled with biosynthesized Ag nanoparticles: New insights to band gap study. Results Phys. 2019, 13, 102220. [CrossRef]

51. Saadiah, M.; Nagao, Y.; Samsudin, A. Proton $\left(\mathrm{H}^{+}\right)$transport properties of CMC-PVA blended polymer solid electrolyte doped with $\mathrm{NH}_{4} \mathrm{NO}_{3}$. Int. J. Hydrogen Energy 2020, 45, 14880-14896. [CrossRef]

52. Bourahla, S.; Benamara, A.A.; Moustefai, S.K. Infrared spectra of inorganic aerosols: Ab initio study of $\left(\mathrm{NH}_{4}\right)_{2} \mathrm{SO}_{4}, \mathrm{NH}_{4} \mathrm{NO}_{3}$, and $\mathrm{NaNO}_{3}$. Can. J. Phys. 2014, 92, 216-221. [CrossRef]

53. Ndruru, S.T.C.L.; Wahyuningrum, D.; Bundjali, B.; Arcana, I.M. Preparation and Characterization of Biopolymer Electrolyte Membranes Based on LiClO4-Complexed Methyl Cellulose as Lithium-ion Battery Separator. J. Eng. Technol. Sci. 2020, 52, 28. [CrossRef]

54. Hafiza, M.; Isa, M. Correlation between structural, ion transport and ionic conductivity of plasticized 2-hydroxyethyl cellulose based solid biopolymer electrolyte. J. Membr. Sci. 2020, 597, 117176. [CrossRef]

55. Aziz, S.B.; Hamsan, M.H.; Brza, M.A.; Kadir, M.F.Z.; Abdulwahid, R.T.; Ghareeb, H.O.; Woo, H.J. Fabrication of energy stor-age EDLC device based on CS:PEO polymer blend electrolytes with high Li+ ion transference number. Results Phys. 2019, 15, 102584. [CrossRef]

56. Amran, N.N.A.; Manan, N.S.A.; Kadir, M.F.Z. The effect of $\mathrm{LiCF}_{3} \mathrm{SO}_{3}$ on the complexation with potato starch-chitosan blend polymer electrolytes. Ionics 2016, 22, 1647-1658. [CrossRef]

57. Aziz, S.B.; Hamsan, M.H.; Nofal, M.M.; Karim, W.O.; Brevik, I.; Brza, M.; Abdulwahid, R.T.; Al-Zangana, S.; Kadir, M.F. Structural, Impedance and Electrochemical Characteristics of Electrical Double Layer Capacitor Devices Based on Chitosan: Dextran Biopolymer Blend Electrolytes. Polymers 2020, 12, 1411. [CrossRef] [PubMed]

58. Shukur, M.F.; Azmi, M.S.; Zawawi, S.M.M.; Majid, N.A.; Illias, H.A.; Kadir, M.F.Z. Conductivity studies of biopolymer elec-trolytes based on chitosan incorporated with NH4Br. Phys. Scr. 2013, T157, 1-5.

59. Mejenom, A.A.; Hafiza, M.N.; Isa, M.I.N. X-Ray diffraction and infrared spectroscopic analysis of solid biopolymer electro-lytes based on dual blend carboxymethyl cellulose-chitosan doped with ammonium bromide. ASM Sci. J. 2018, 11, 37-46.

60. Poy, S.Y.; Bashir, S.; Omar, F.S.; Saidi, N.M.; Farhana, N.K.; Sundararajan, V.; Ramesh, K.; Ramesh, S. Poly (1-vinylpyrrolidone-covinyl acetate) (PVP-co-VAc) based gel polymer electrolytes for electric double layer capacitors (EDLC). J. Polym. Res. 2020, 27, 50. [CrossRef]

61. Pistorius, A.M.A.; DeGrip, W.J. Deconvolution as a tool to remove fringes from an FT-IR spectrum. Vib. Spectrosc. 2004, 36, 89-95. [CrossRef]

62. Ramlli, M.A.; Bashirah, N.A.A.; Isa, M.I.N. Ionic Conductivity and Structural Analysis of 2-hyroxyethyl Cellulose Doped with Glycolic Acid Solid Biopolymer Electrolytes for Solid Proton Battery. IOP Conf. Ser. Mater. Sci. Eng. 2018, 440, 012038. [CrossRef]

63. Kamarudin, K.H.; Isa, M.I.N. Structural and DC Ionic conductivity studies of carboxy methylcellulose doped with ammoni-um nitrate as solid polymer electrolytes. Int. J. Phys. Sci. 2013, 8, 1581-1587.

64. Hafiza, M.; Isa, M. Solid polymer electrolyte production from 2-hydroxyethyl cellulose: Effect of ammonium nitrate composition on its structural properties. Carbohydr. Polym. 2017, 165, 123-131. [CrossRef]

65. Ramlli, M.A.; Isa, M.I.N. Structural and Ionic Transport Properties of Protonic Conducting Solid Biopolymer Electrolytes Based on Carboxymethyl Cellulose Doped with Ammonium Fluoride. J. Phys. Chem. B 2016, 120, 11567-11573. [CrossRef] [PubMed]

66. Rasali, N.M.J.; Nagao, Y.; Samsudin, A.S. Enhancement on amorphous phase in solid biopolymer electrolyte based alginate doped $\mathrm{NH}_{4} \mathrm{NO}_{3}$. Ionics 2018, 25, 641-654. [CrossRef]

67. Rani, M.S.A.; Mohamed, N.S.; Isa, M.I.N. Investigation of the Ionic Conduction Mechanism in Carboxymethyl Cellu-lose/Chitosan Biopolymer Blend Electrolyte Impregnated with Ammonium Nitrate. Int. J. Polym. Anal. Charact. 2015, 20, 491-503. [CrossRef]

68. Aniskari, N.A.B.; Mohd Isa, M.I.N. The effect of ionic charge carriers in 2-hydroxyethyl cellulose solid biopolymer electro-lytes doped glycolic acid via FTIR-deconvolution technique. J. Sustain. Sci. Manag. 2017, 12, 71-79.

69. Ahmad, N.H.B.; Isa, M.I.N.B.M. Proton conducting solid polymer electrolytes based carboxymethyl cellulose doped ammo-nium chloride: Ionic conductivity and transport studies. Int. J. Plast. Technol. 2015, 19, 47-55. [CrossRef] 
70. Samsudin, A.S.; Kuan, E.C.H.; Isa, M.I.N. Investigation of the Potential of Proton-Conducting Biopolymer Electrolytes Based Methyl Cellulose-Glycolic Acid. Int. J. Polym. Anal. Charact. 2011, 16, 477-485. [CrossRef]

71. Zainuddin, N.K.; Rasali, N.M.J.; Samsudin, A.S. Study on the effect of PEG in ionic transport for CMC-NH4Br-based solid polymer electrolyte. Ionics 2018, 24, 3039-3052. [CrossRef]

72. Nofal, M.M.; Aziz, S.B.; Hadi, J.M.; Abdulwahid, R.T.; Dannoun, E.M.A.; Marif, A.S.; Al-Zangana, S.; Zafar, Q.; Brza, M.A.; Kadir M.F.Z. Synthesis of Porous Proton Ion Conducting Solid Polymer Blend Electrolytes Based on PVA: CS Polymers: Structural, Morphological and Electrochemical Properties. Materials 2020, 13, 4890. [CrossRef]

73. Rani, M.S.A.; Ahmad, A.; Mohamed, N.S. Influence of nano-sized fumed silica on physicochemical and electrochemical properties of cellulose derivatives-ionic liquid biopolymer electrolytes. Ionics 2018, 24, 807-814. [CrossRef]

74. Jaipal Reddy, M.; Chu, P.P. Effect of $\mathrm{Mg}^{2+}$ on PEO morphology and conductivity. Solid State Ionics 2002, 149, 115. [CrossRef]

75. Vijaya, N.; Selvasekarapandian, S.; Malathi, J.; Iwai, Y.; Nithya, H.; Kawamura, J. NMR study on PVP-NH4Cl based-proton con-ducting polymer electrolyte. Indian J. Appl. Res. 2013, 3, 506-510. [CrossRef]

76. Samsi, N.S.; Ali, R.M.; Zakaria, R.; Yahya, M.Z.A.; Ali, A.M.M. Electrical Properties of Ammonium Iodide Doped Cellulose Acetate Based Polymer Electrolyte. ICGSCE 2015, 2014, 331-338.

77. Jibreel, U.M.; Bhattacharya, B. Synthesis, Characterization, and Detailed Studies onPlasticizedPoly(ethyl meth-acrylate): NH4I PolymerElectrolyte. Adv. Polym. Technol. 2018, 37, 21693. [CrossRef]

78. Alia, R.M.; Haruna, N.I.; Alia, A.M.M.; Yahya, M.Z.A. Effect of ZnSDispersoid in Structural and Electrical Proper-ties of Plasticized CA-NH4I. Phys. Procedia 2012, 25, 293-298. [CrossRef]

79. Pande, G.P.; Kumar, Y.; Hashmi, S.A. Ionic liquid incorporated polymer electrolytes for supercapacitor application. Indian J. Chem. 2010, 49, 743-751. Available online: http:/ / hdl.handle.net/123456789/9673 (accessed on 20 January 2021).

80. Sampathkumar, L.; Selvin, P.C.; Selvasekarapandian, S.; Perumal, P.; Chitra, R.; Muthukrishnan, M. Synthesis and characterization of biopolymer electrolyte based on tamarind seed polysaccharide, lithium perchlorate and ethylene carbonate for electrochemical applications. Ionics 2019, 25, 1067-1082. [CrossRef]

81. Monisha, S.; Mathavan, T.; Selvasekarapandian, S.; Benial, A.M.F.; Latha, M.P. Preparation and characterization of cellulose acetate and lithium nitrate for advanced electrochemical devices. Ionics 2017, 23, 2697-2706. [CrossRef]

82. $\mathrm{Ng}$, L.; Mohamad, A. Effect of temperature on the performance of proton batteries based on chitosan-NH4NO3-EC membrane. J. Membr. Sci. 2008, 325, 653-657. [CrossRef]

83. Woo, H.J.; Liew, C.; Majid, S.R.; Arof, A.K. Poly ( $\varepsilon$ - caprolactone)-based polymer electrolyte for electrical doublelayer ca-pacitors. High Perform. Polym. 2014, 26, 637-640. [CrossRef]

84. Hadi, J.M.; Aziz, S.B.; Saeed, S.R.; Brza, M.A.; Abdulwahid, R.T.; Hamsan, M.H.; Abdullah, R.M.; Kadir, M.F.Z.; Muzakir, S.K. Investigation of Ion Transport Parameters and Electrochemical Performance of Plasticized Biocompatible Chitosan-Based Proton Conducting Polymer Composite Electrolytes. Membranes 2020, 10, 363. [CrossRef] [PubMed]

85. Aziz, S.B.; Hadi, J.M.; Dannoun, E.M.A.; Abdulwahid, R.T.; Saeed, S.R.; Marf, A.S.; Karim, W.O.; Kadir, M.F. The Study of Plasticized Amorphous Biopolymer Blend Electrolytes Based on Polyvinyl Alcohol (PVA): Chitosan with High Ion Conductivity for Energy Storage Electrical Double-Layer Capacitors (EDLC) Device Application. Polymers 2020, 12, 1938. [CrossRef] [PubMed]

86. Liew, C.-W.; Ramesh, S.; Arof, A.K. Good prospect of ionic liquid based-poly(vinyl alcohol) polymer electrolytes for supercapacitors with excellent electrical, electrochemical and thermal properties. Int. J. Hydrogen Energy 2014, 39, $2953-2963$. [CrossRef]

87. Shuhaimi, N.E.A.; Teo, L.P.; Woo, H.J.; Majid, S.R.; Arof, A.K. Electrical double-layer capacitors with plasticized polymer electrolyte based on methyl cellulose. Polym. Bull. 2012, 69, 807-826. [CrossRef]

88. Kumar, M.S.; Bhat, D.K. Polyvinyl alcohol-polystyrene sulphonic acid blend electrolyte for supercapacitor application. Phys. $B$ Condens. Matter 2009, 404, 1143-1147. [CrossRef]

89. Andres, B.; Dahlström, C.; Blomquist, N.; Norgren, M.; Olin, H. Cellulose binders for electric double-layer capacitor electrodes: The influence of cellulose quality on electrical properties. Mater. Des. 2018, 141, 342-349. [CrossRef]

90. Shukur, M.F. Characterization of Ion Conducting Solid Biopolymer Electrolytes Based on Starch-chitosan Blend and Appli-cation in Electrochemical Devices. Ph.D. Thesis, University of Malaya, Kuala Lumpur, Malaysia, 2015.

91. Winie, T.; Jamal, A.; Saaid, F.I.; Tseng, T.-Y. Hexanoyl chitosan/ENR25 blend polymer electrolyte system for electrical dou-ble layer capacitor. Polym. Adv. Technol. 2018, 30,1-10.

92. Yassine, M.; Fabris, D. Performance of Commercially Available Supercapacitors. Energies 2017, 10, 1340. [CrossRef] 